\title{
Axillary Lymph Node Swelling Mimicking Breast Cancer Metastasis After COVID-19 Vaccination: A Japanese Case Report and Literature Review
}

\author{
NOBUYASU YOSHIMOTO ${ }^{1,2}$, KOHEI TAKURA $^{3}$, AKEMI YANAGI $^{4}$, SATORU TAKAYAMA $^{3}$, \\ MASAKI SAKAMOTO ${ }^{3}$, KEN ISHIKAWA $^{3}$, TAKEYASU KATADA ${ }^{3}$, AKIFUMI KAWATE $^{3}$, SHORYU TAKAYAMA $^{3}$, \\ MASAKATSU YAMASHITA ${ }^{3}$, SHINYA YAMAMOTO $^{3}$, KIOTO YOKOYAMA $^{3}$ and HISANORI KANI ${ }^{3}$ \\ ${ }^{1}$ Department of Breast Surgery, Nagoya Tokushukai General Hospital, Kasugai, Japan; \\ ${ }^{2}$ Clinical Research Center, Nagoya Tokushukai General Hospital, Kasugai, Japan; \\ ${ }^{3}$ Department of Surgery, Nagoya Tokushukai General Hospital, Kasugai, Japan; \\ ${ }^{4}$ Department of Radiology, Nagoya Tokushukai General Hospital, Kasugai, Japan
}

\begin{abstract}
Background/Aim: COVID-19 started to spread as a pandemic in December 2019 and COVID-19 vaccination has been initiated worldwide. The efficacy of vaccination has been scientifically proven, but it might cause axillary lymph node swelling. To diagnose patients with axillary lymph node swelling caused by COVID-19 vaccination, we herein reviewed existing literature on this symptom. Case Report: We report the case of a 70-year-old woman with a breast tumour. She had undergone cecum cancer surgery and regular computed tomography $(C T)$. During breast tumour follow-up, she received scheduled CT that indicated severe axillary lymph node swelling mimicking breast cancer metastasis. We performed aspiration biopsy cytology of that lymph node, and determined this was not cancer metastasis but an effect of the COVID-19 vaccine. We confirmed this diagnosis at one month after computed tomography showed that the lymph node swelling had improved. Conclusion: Axillary lymph node swelling can occur after COVID-19 vaccination. Therefore, it is important to consider the effect of the COVID-19 vaccination on axillary lymph node swelling when diagnosing breast tumours.
\end{abstract}

This article is freely accessible online.

Correspondence to: Nobuyasu Yoshimoto, MD, Ph.D., Department of Breast Surgery, Nagoya Tokushukai General Hospital, 2-52, Kozojicho-Kita, Kasugai-Shi, Aichi, 487-0016, Japan. Tel: +81 568518711, Fax: +81 568517115, e-mail: paris@s4.dion.ne.jp

Key Words: COVID-19 vaccine, axillary lymph node swelling, breast cancer.
SARS-CoV-2 infection disease was first reported in Wuhan in December 2019 (1) and we are still in effect of this pandemic both in Japan and globally. Of note, cancer patient diagnoses and treatment are being formed under these pandemic conditions. SARS-CoV-2 vaccines were rapidly developed, including the mRNA vaccine (2), which has specific side-effects including fever, general fatigue, and upper arm swelling in the region of the vaccine injection.

In Japan, the vaccination of medical staff and elderly people started in February 2021. Currently, there are increasing numbers of people who have received vaccination twice. Therefore, the chance of encountering double vaccinated people in daily clinical practice is increasing. There are some guidelines for the timing of the vaccine injection for cancer patients, such as the National Comprehensive Cancer Network guidelines (3), but it is still not clear how these vaccines might influence cancer diagnosis and treatment, especially for breast cancer. Herein, we present a case with severe axillary lymph node swelling thought to be caused by the COVID-19 vaccine injection, which was similar to breast cancer metastasis observed by computed tomography (CT), and present a literature review of the effect of COVID-19 vaccination on axillary lymph nodes.

\section{Case Report}

The patient was a 70-year-old woman who was diagnosed with cecum cancer in December 2019, and who underwent surgery in February 2020. The pathological finding was adenocarcinoma, $\mathrm{t}=25 \mathrm{~mm}$, with no lymph node metastasis. She received no adjuvant therapy. A follow-up of cecum cancer by enhanced CT in July 2020 indicated a left breast tumour. Then, she was introduced to the breast surgery clinic. She had no palpated mass, had focal asymmetric density in 


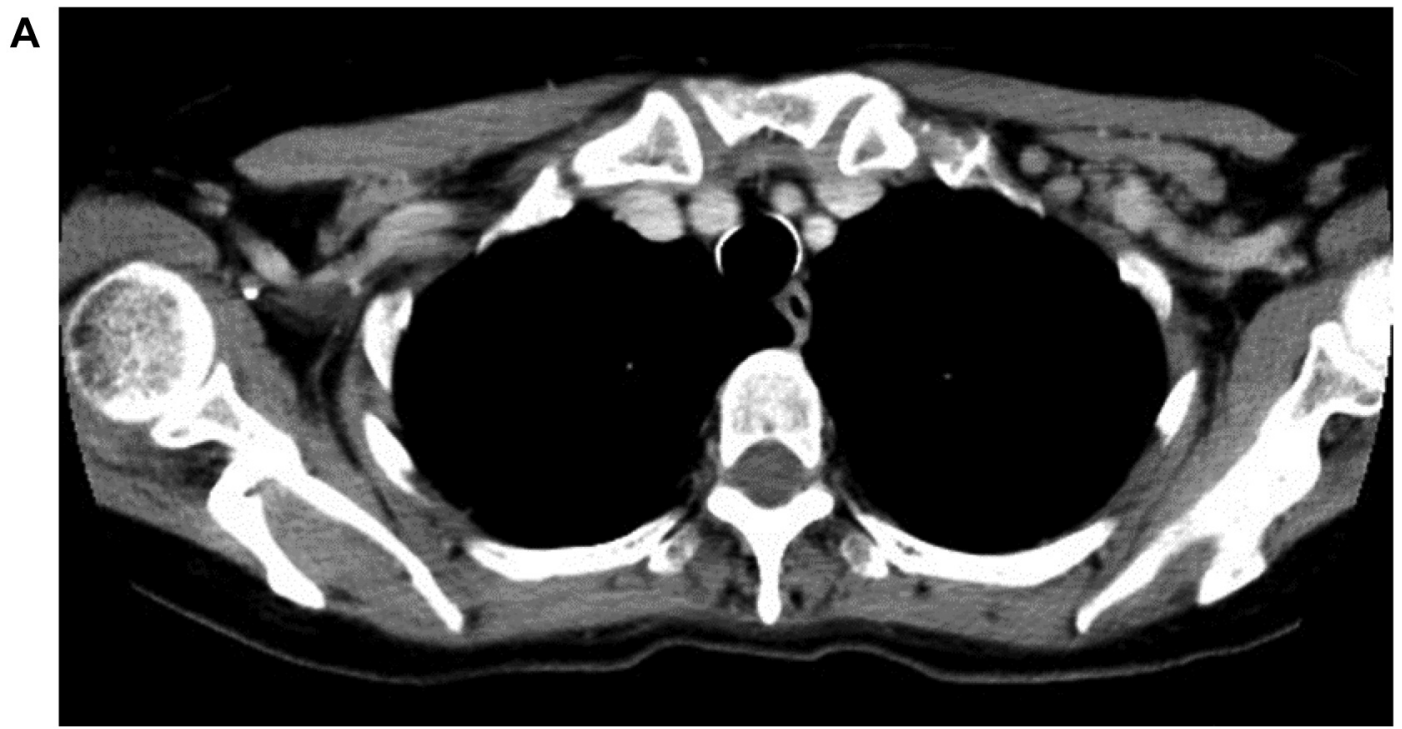

B

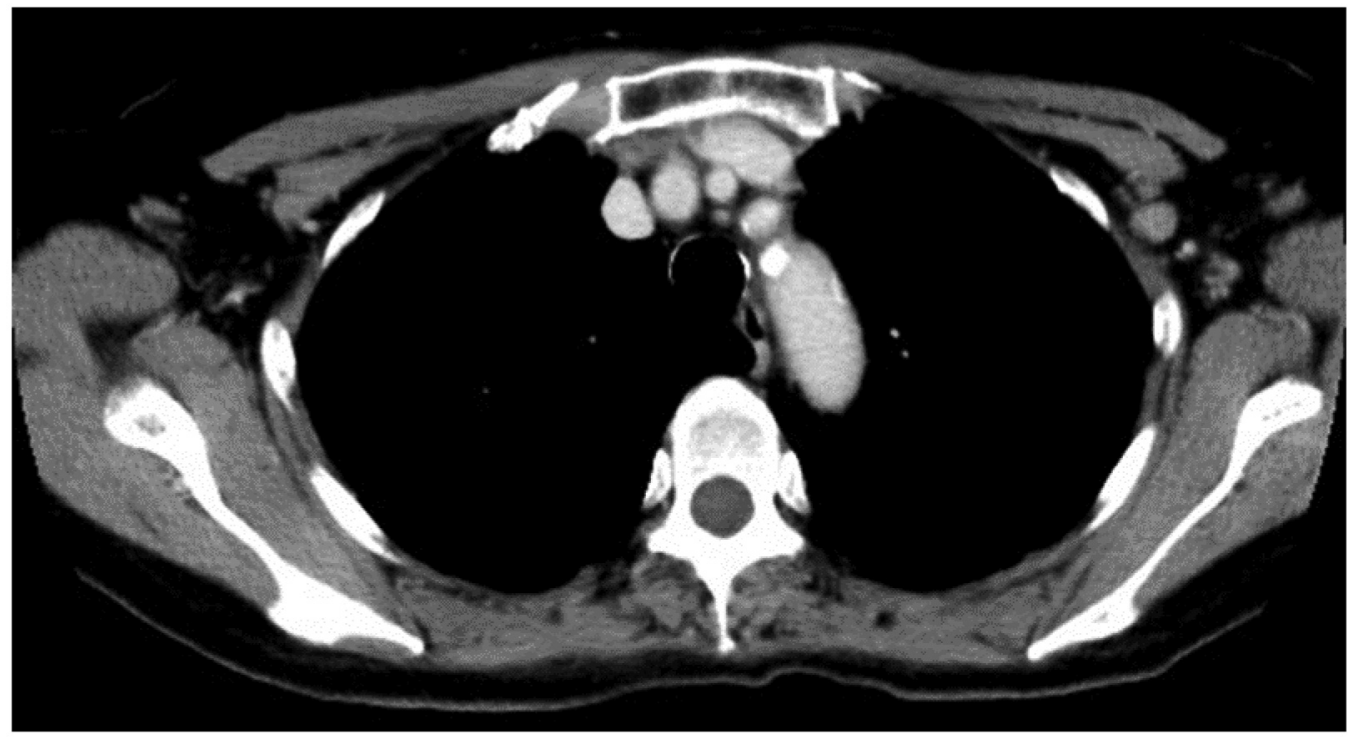

Figure 1. Enhanced computed tomography (CT) (June 2021) shows severe axillary lymph node swelling mimicking breast cancer metastasis at level $I(B)$ and level II $(A)$.

the left upper outer quadrant of the mammogram, and the tumour in her left breast appeared benign by ultrasonography at the first visit to the breast surgery clinic. We planned a follow up. On June 2021, she received an enhanced CT to check for distant metastasis related to cecum cancer, and severe swelling of levels I and II was observed in the axillary lymph node (Figure 1A and B). However, the tumour in her left breast did not get larger. We considered that precise checking was required, so we called her to the breast surgery clinic earlier than originally suggested. She came to our clinic in July 2021, 2 weeks after undergoing CT.

The patient underwent a medical interview and we performed local palpation, mammogram, and ultrasonography.
In addition, we performed aspiration biopsy cytology (ABC) of the left breast tumour and the swollen left level I axillary lymph node. The medical interview indicated that 3 days before she underwent the CT, she received a second COVID19 vaccination on her left upper arm and developed low grade fever, upper arm pain, and swelling as a side effect of the vaccination. Local palpation indicated no abnormalities and there was no palpable lymph node in her left axilla. The mammogram showed a left upper outer mass that had not changed from one year before retrospectively (Figure 2A and B). Ultrasonography showed the left breast mass had not changed in size or shape from one year before (Figure 2C); however, it indicated a new swollen left axillary lymph node 

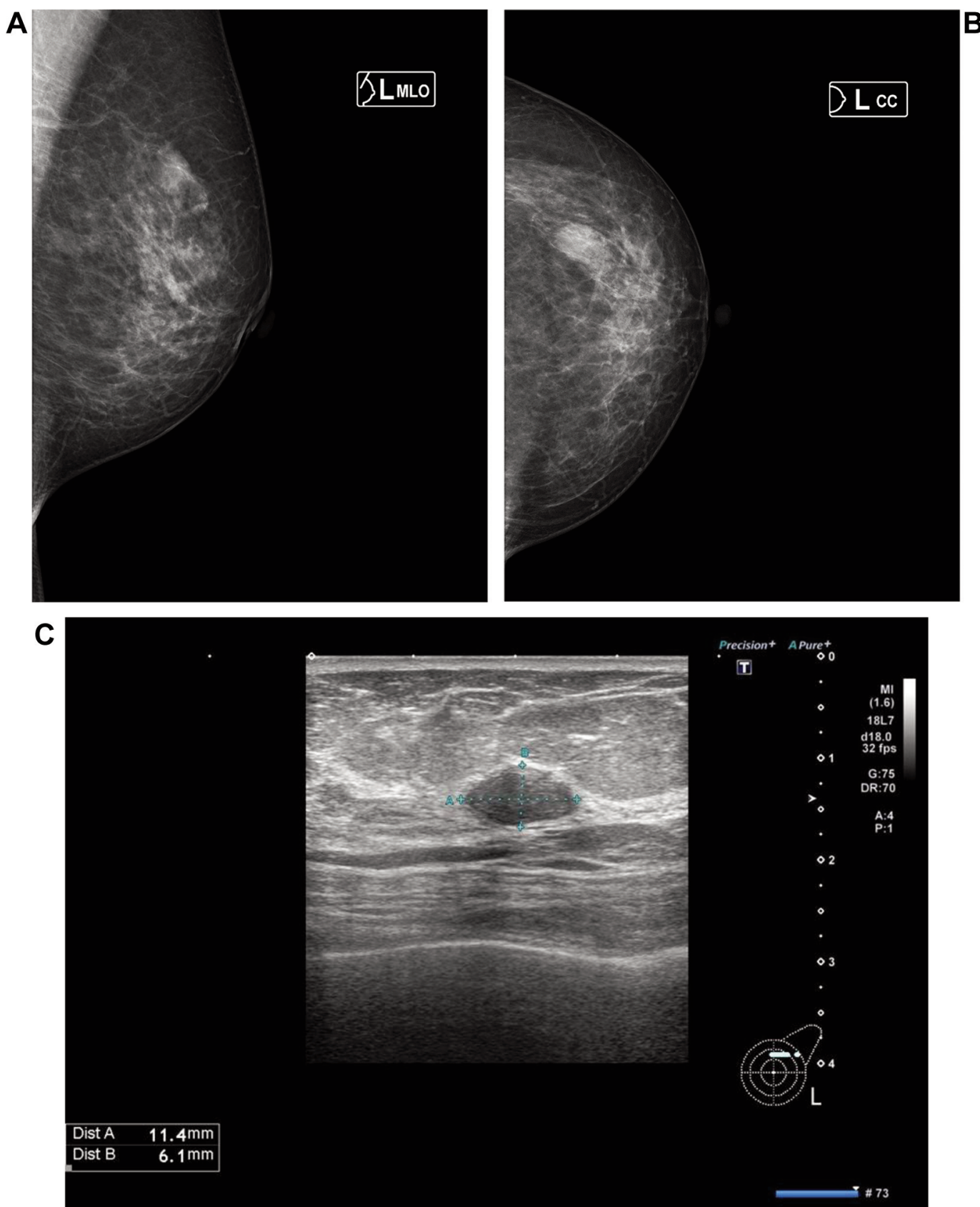

Figure 2. Continued

(Figure 2D and E). Except for this swollen lymph node of level II, the appearance of most lymph nodes indicated they were undergoing an inflammatory response because they maintained the structure of the cortex and medulla. The ABC of the breast tumour specimen was inadequate and it was negative for the axillary lymph node. A blood exam performed on the same day as the enhanced CT in June 2021 showed CRP was slightly high at 1.82. We diagnosed the swollen lymph nodes as a vaccine side-effect. We planned to follow-up the patient as before. We also performed a simple CT to check the axillary lymph nodes on the same day as these precise checks in July 2021 and found the swelling had improved (Figure 3A and B).

Written informed consent was obtained from the patient for the publication of this Case Report and any accompanying images. This was a case report and therefore we did not require additional permission from our review board. 

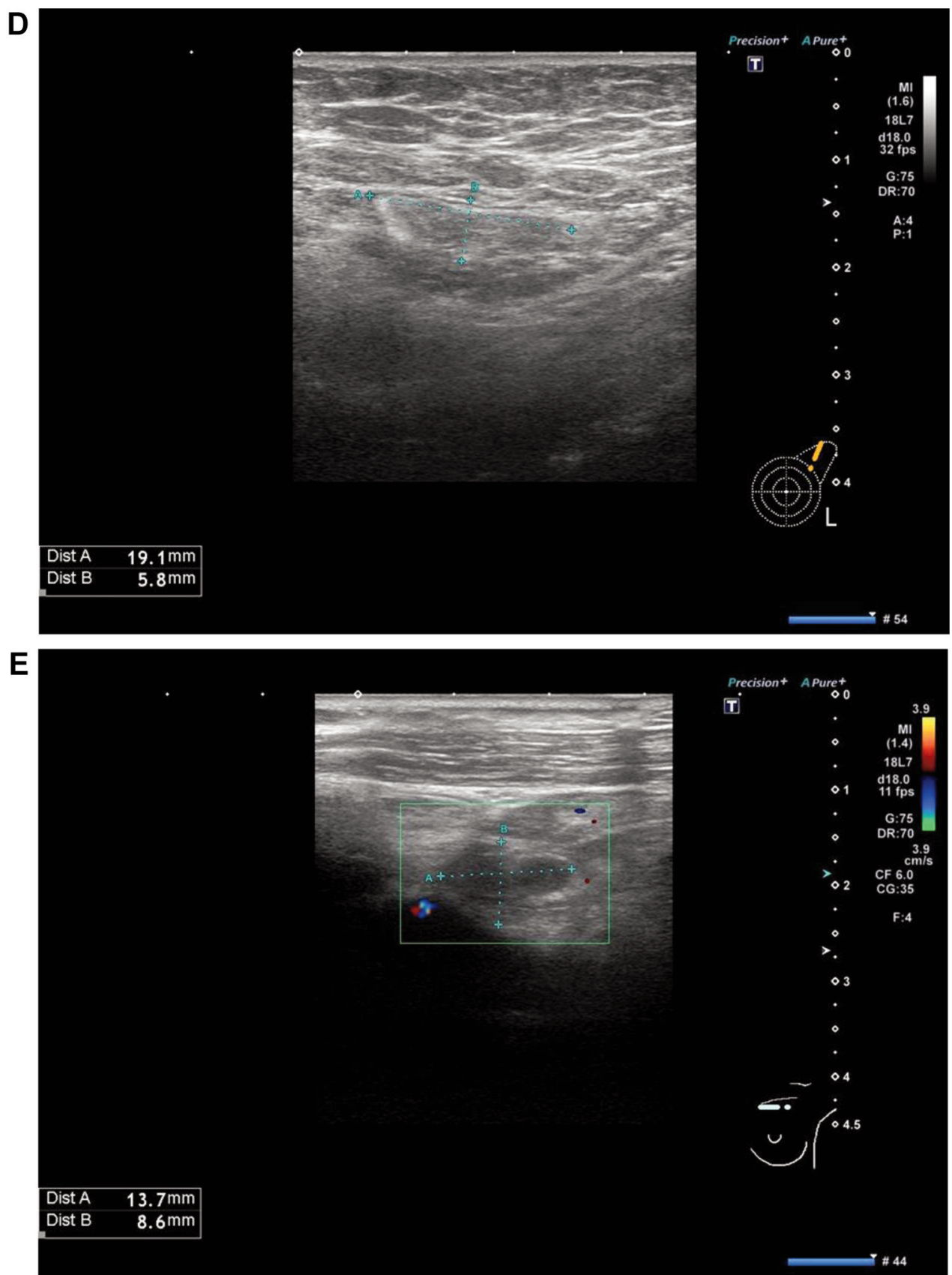

Figure 2. Mammogram and ultrasonography (July 2021). The mammogram shows a left upper outer mass (A, B). Ultrasonography (US) shows an oval mass in the left $C$ area $(C)$ and lymph node swelling at level $I(D)$ and level II $(E)$. We performed US guided aspiration biopsy cytology for this breast mass and level I lymph node.

\section{Discussion}

In Japan, the number of COVID-19 patients increased again in July 2021, which was called "the 5th wave" in the Tokyo metropolitan area. Of note, the COVID-19 vaccine injection became popular among elderly people. Although the number of COVID-19 patients is increasing, the number of elderly patients is decreasing. The COVID-19 vaccine is the first approved mRNA vaccine and although it reduces the risk of COVID-19 infection (2) it causes specific side-effects such as fever, general fatigue, and upper arm swelling that have not been experienced with other vaccines. In breast tumour 


\section{A}

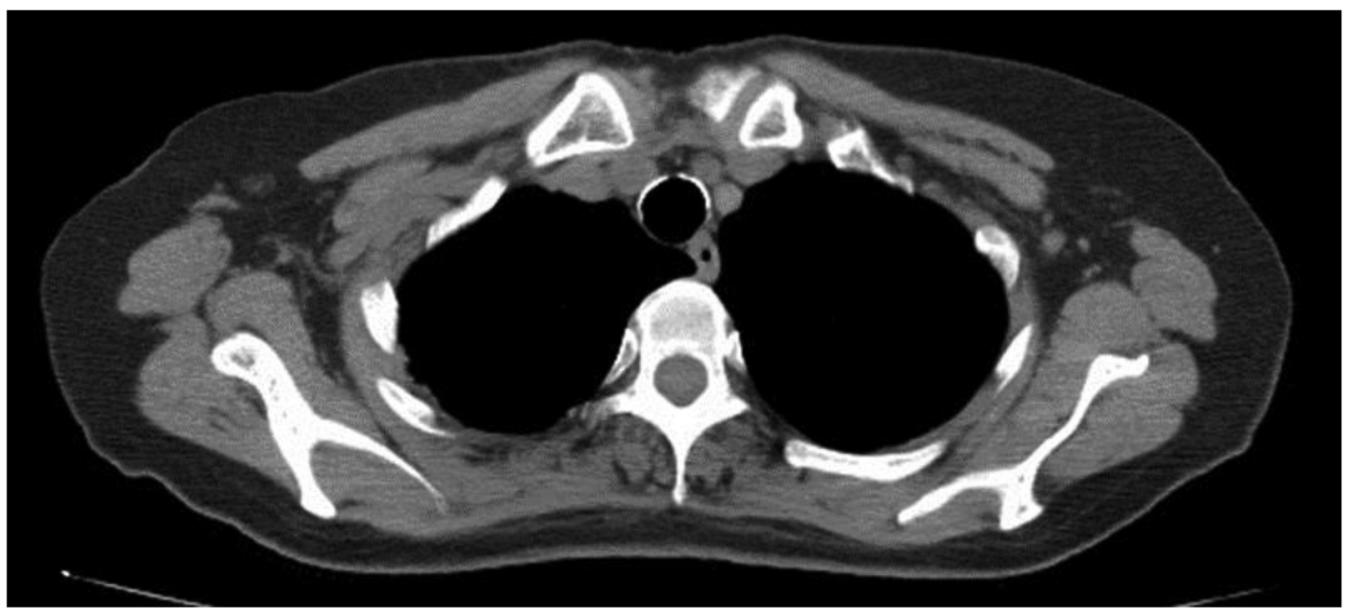

B

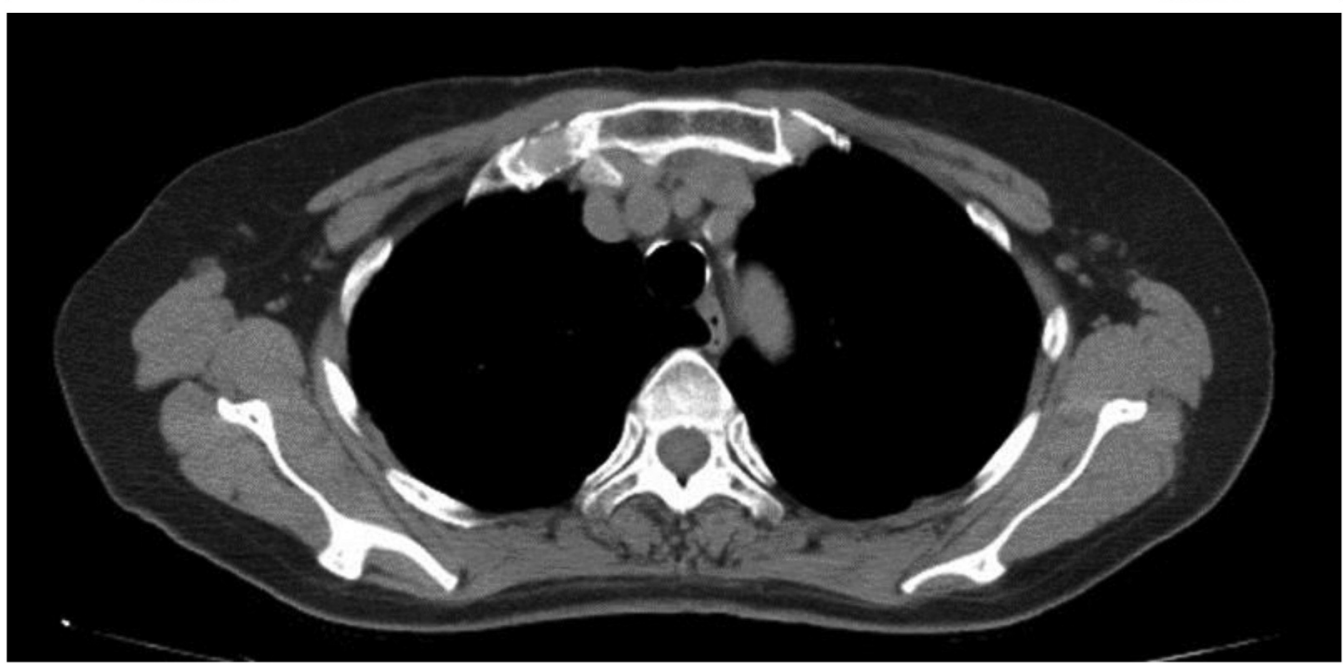

Figure 3. Simple computed tomography (CT) (July 2021) shows the axillary lymph node swelling had improved at both level I (B) and level II (A).

diagnosis, axillary lymph node information is very important; if they are swollen it is important to determine whether they are malignant. When we encountered this patient, it was not well known in Japan that axillary lymph node might swell after COVID-19 vaccination. This was the main reason of misconception for this patient. From this point of view, previous reports indicated a hot spot present in the area of axillary lymph nodes by PET-CT (4-8). In this case, CT was used to determine severe axillary lymph node swelling mimicking breast cancer metastasis; however, we did not diagnose breast cancer metastasis but rather the influence of the COVID-19 vaccine on the basis of the following: ultrasonography indicated normal lymph node structure including the cortex and medulla; CRP was evaluated on the same day as the enhanced CT was performed (June 2021); and the lymph node size was reduced at the follow-up CT, which is more objective than ultrasonography.
In Israel, a massive vaccination program was started in December 2020, relatively earlier than in other countries. Faermann et al. reported the analysis of 163 cases who presented with ipsilateral lymphadenopathy and history of a recent COVID-19 vaccination in the ipsilateral arm. They showed lymph node cortical thickening was significantly thinner 4-5 weeks after the 2 nd vaccination dose (9). This point might be useful for different diagnosis, as in our case. These findings might help us avoid unnecessary biopsies as suggested by Ozutemiz et al. (10). Therefore, we should try to reduce patient anxiety but also avoid further delays in vaccinations and breast cancer screening (11). Furthermore, another study reported cervical or neck lymphadenopathy (12-13), or 18F-FDG PET/CT uptake in a subdiaphragmatic lymph node (14) after vaccination against COVID-19. Currently, the optimal timing for breast cancer surgery and COVID-19 vaccination are still under discussion (15). In the 
first place, fatality rate of COVID-19 seems to be different from country to country. Greece is the lowest actual number of deaths among European countries with a comparable population (16).

The major limitation of this case report was that only one case was analysed. There might be many cases of breast cancer that lack severe axillary lymph node swelling after COVID-19 vaccination. It is hoped that we can collect data for more cases with a breast tumour or breast cancer, which will allow us to achieve the correct diagnosis.

\section{Conclusion}

Vaccination is important for the control of COVID-19 infection. At the same time, clinical oncologists, and especially breast oncologists, should carefully diagnose breast tumours because COVID-19 vaccination could bring on axillary lymph node swelling that is mimicking breast cancer metastasis, as in the case presented herein.

\section{Conflicts of Interest}

The Authors report no conflicts of interest.

\section{Authors' Contributions}

Research design: Yoshimoto N; collection and analysis of data: Yoshimoto N, Takura K, Yanagi A; all Authors read and approved the final article.

\section{References}

1 Zhu N, Zhang D, Wang W, Li X, Yang B, Song J, Zhao X, Huang B, Shi W, Lu R, Niu P, Zhan F, Ma X, Wang D, Xu W, Wu G, Gao GF, Tan $\mathrm{W}$ and China Novel Coronavirus Investigating and Research Team: A novel Coronavirus from patients with pneumonia in China, 2019. N Engl J Med 382(8): 727-733, 2020. PMID: 31978945. DOI: 10.1056/NEJMoa2001017

2 Polack FP, Thomas SJ, Kitchin N, Absalon J, Gurtman A, Lockhart S, Perez JL, Pérez Marc G, Moreira ED, Zerbini C, Bailey R, Swanson KA, Roychoudhury S, Koury K, Li P, Kalina WV, Cooper D, Frenck RW Jr, Hammitt LL, Türeci Ö, Nell H, Schaefer A, Ünal S, Tresnan DB, Mather S, Dormitzer PR, Şahin U, Jansen KU, Gruber WC and C4591001 Clinical Trial Group: Safety and efficacy of the BNT162b2 mRNA Covid-19 vaccine. N Engl J Med 383(27): 2603-2615, 2020. PMID: 33301246. DOI: 10.1056/NEJMoa2034577

3 National Comprehensive Cancer Network. COVID-19 Vaccination and cancer patients. Available at: https://www.ncen.org/covid-19 [Last accessed on September 21, 2021]

4 Shah S, Wagner T, Nathan M and Szyszko T: COVID-19 vaccine-related lymph node activation - patterns of uptake on PET-CT. BJR Case Rep 7(3): 20210040, 2021. PMID: 34131510. DOI: 10.1259/bjrcr.20210040

5 Singh B, Kaur P, Kumar V and Maroules M: COVID-19 vaccine induced axillary and pectoral lymphadenopathy on PET scan.
Radiol Case Rep 16(7): 1819-1821, 2021. PMID: 33968285. DOI: $10.1016 /$ j.radcr.2021.04.053

6 Brown AH, Shah S, Groves AM, Wan S and Malhotra A: The challenge of staging breast cancer with PET/CT in the era of COVID vaccination. Clin Nucl Med 46(12): 1006-1010, 2021. PMID: 33795590. DOI: 10.1097/RLU.0000000000003683

7 Schapiro R, Moncayo VM and Meisel JL: Case report of lymph node activation mimicking cancer progression: A false positive F18 FDG PET CT after COVID-19 vaccination. Curr Probl Cancer Case Rep 4: 100092, 2021. PMID: 34308402. DOI: 10.1016/j.cpccr.2021.100092

8 Cohen D, Krauthammer SH, Wolf I and Even-Sapir E: Hypermetabolic lymphadenopathy following administration of BNT162b2 mRNA Covid-19 vaccine: incidence assessed by [ $\left.{ }^{18} \mathrm{~F}\right]$ FDG PET-CT and relevance to study interpretation. Eur $\mathbf{J}$ Nucl Med Mol Imaging 48(6): 1854-1863, 2021. PMID: 33774684. DOI: $10.1007 / \mathrm{s} 00259-021-05314-2$

9 Faermann R, Nissan N, Halshtok-Neiman O, Shalmon A, Gotlieb M, Yagil Y, Samoocha D, Friedman E and Sklair-Levy M: COVID-19 vaccination induced lymphadenopathy in a specialized breast imaging clinic in Israel: Analysis of 163 cases. Acad Radiol 28(9): 1191-1197, 2021. PMID: 34257025. DOI: 10.1016/j.acra.2021.06.003

10 Özütemiz C, Krystosek LA, Church AL, Chauhan A, Ellermann JM, Domingo-Musibay E and Steinberger D: Lymphadenopathy in COVID-19 vaccine recipients: diagnostic dilemma in oncologic patients. Radiology 300(1): E296-E300, 2021. PMID: 33625300. DOI: 10.1148/radiol.2021210275

11 Lehman CD, Lamb LR and D'Alessandro HA: Mitigating the impact of Coronavirus disease (COVID-19) vaccinations on patients undergoing breast imaging examinations: a pragmatic approach. AJR Am J Roentgenol 217(3): 584-586, 2021. PMID: 33617288. DOI: 10.2214/AJR.21.25688

12 Cardoso F, Reis A, Osório C, Scigliano H and Nora M: A case of cervical lymphadenopathy after vaccination against COVID19. Cureus 13(5): e15050, 2021. PMID: 34141500. DOI: $10.7759 /$ cureus. 15050

13 Mitchell OR, Couzins M, Dave R, Bekker J and Brennan PA: COVID-19 vaccination and low cervical lymphadenopathy in the two week neck lump clinic - a follow up audit. Br J Oral Maxillofac Surg 59(6): 720-721, 2021. PMID: 33947605. DOI: 10.1016/j.bjoms.2021.04.008

14 Quak E, Morel A, Faudemer J, Levy C and Ciappuccini R: Subdiaphragmatic lymph nodes uptake on 18F-FDG PET/CT after COVID-19 vaccination in the thigh. Clin Nucl Med, 2021. PMID: 34661560. DOI: 10.1097/RLU.0000000000003941

15 Ko G, Hota S and Cil TD: COVID-19 vaccination and breast cancer surgery timing. Breast Cancer Res Treat 188(3): 825-826, 2021. PMID: 34156582. DOI: 10.1007/s10549-021-06293-6

16 Delinasios GJ, Fragkou PC, Gkirmpa AM, Tsangaris G, Hoffman RM and Anagnostopoulos AK: The experience of Greece as a model to contain COVID-19 infection spread. In Vivo 35(2): 12851294, 2021. PMID: 33622932. DOI: 10.21873/invivo.12380

Received November 2, 2021

Revised November 20, 2021

Accepted December 10, 2021 